Boise State University

ScholarWorks

Counselor Education Faculty Publications and

Presentations

Department of Counselor Education

$7-1-2018$

\title{
Re-Thinking Bullying Interventions for High School Students: A Qualitative Study
}

\author{
Aida Midgett \\ Boise State University \\ Diana M. Doumas \\ Boise State University \\ April Johnston \\ Boise State University \\ Rhiannon Trull \\ Boise State University \\ Raissa Miller \\ Boise State University
}


This is an author-produced, peer-reviewed version of this article. The final, definitive version of this document can be found online at Journal of Child and Adolescent Counseling, published by Taylor \& Francis. Copyright restrictions may apply .doi: 10.1039/c7ta01026e

\title{
Re-Thinking Bullying Interventions for High School Students: A Qualitative Study
}

\author{
Aida Midgett \\ Boise State University \\ Diana M. Doumas \\ Boise State University
}

\author{
April Johnston \\ Boise State University \\ Rhiannon Trull \\ Boise State University
}

\begin{abstract}
The purpose of this study was to obtain feedback to inform a modification of a brief, schoolbased bullying intervention originally developed for elementary and middle school students to be age appropriate for the high school level. We investigated the in-depth, inner experiences of high school students randomly selected to participate in a brief, bystander bullying intervention program. Thorough qualitative analysis, we found students spoke about (a) the complexity of bullying in high school, (b) cyberbullying and increased potential consequences related to social media, (c) the normalization and minimization of bullying, (d) lack of adult support, (e) an appreciation for the program's strategies for students to take action, and (f) the importance of training activities to help build rapport and increase awareness. We discuss implications for counselors and counselor educators based on our findings.
\end{abstract}

Keywords: bullying, bystander intervention, STAC, high school, school counseling

Bullying represents a significant problem for school-aged youth in the United States (Polanin \& Vera, 2013). Researchers have defined bullying as "the repeated oppression, psychological or physical, of a less powerful person by a more powerful individual or group of persons" (Rigby, 2007, p.15). According to the Center for Disease Control and Prevention (CDCP, 2016b), bullying includes aggression that can be verbal, physical, or relational in nature, as well as aggression that occurs through the use of technology (e.g., cyberbullying). Current national data indicate approximately $21.5 \%$ of students between the ages of $12-18$ report being bullied at school (U.S. Department of Education, 2015). The actual prevalence of bullying, however, may be higher as research indicates only $36 \%$ of students who are victimized report being bullied (Petrosino, Guckenburg, DeVoe, \& Hanson, 2010). This level of underreporting indicates that victims may not be comfortable reporting bullying, suggesting it is important to find ways to increase their comfort level or to train and encourage peers who witness bullying (e.g., bystanders) to report incidents to school personnel.

Although bullying peaks in middle school, bullying behavior continues through high school, with $20.2 \%$ of high school students reporting being bullied on school property and $15.8 \%$ reporting being a victim of cyberbullying (CDCP, 2016a). High school students who are victims of in-person bullying or cyberbullying report higher levels of risky health behaviors, including being physically inactive, getting less sleep, and engaging in risky sexual behaviors, compared to students who are not victimized (Hertz, Donato, \& Wright, 2013). Further, high school students who are victims of in-person bullying report increased injuries due to physical fights and dating violence (Dukes, Stein, \& Zane, 2010). Additionally, high school students who report being bullied are at risk for depression and suicidal ideation (Hertz et al., 2013), as well as suicide attempts later in life (Lomek et al., 2011). Although bullying remains a significant issue at the high school level, the majority of the bullying intervention literature focuses on the elementary and middle school level (Denny et al., 2015; Evans, Fraser, \& Cotter, 2014). Further, a recent meta-analysis indicates that although bullying prevention programs yield positive effects for student in grades seven and younger, these effects drop off sharply for older adolescents (Yeager, Fong, Lee, \& Espelage, 2015). Thus, there is a need for researchers to develop effective school-based bullying intervention programs for high school students. 
This is an author-produced, peer-reviewed version of this article. The final, definitive version of this document can be found online at Journal of Child and Adolescent Counseling, published by Taylor \& Francis. Copyright restrictions may apply .doi: 10.1039/c7ta01026e

\section{A Bystander Approach to Intervention}

One approach to decreasing bullying in schools is to provide interventions specifically targeting student bystander behavior. A significant number of students witness bullying at school, with estimates ranging from $70-88 \%$ (Rivers, Poteat, Noret, \& Ashurst, 2009). Findings indicate that of the $55 \%$ of students in a recent study classified as bystanders (i.e., students who witness bullying, do not engage in bullying, and are not victims), $46 \%$ do nothing to intervene (Datta, Cornell, \& Huang, 2016). This finding is important because when students intervene and/or console the victim, acting as "defenders" (Salmivalli, Lagerspetz, Björkqvist, Österman, \& Kaukiainen, 1996, p.15), bullying behavior decreases (Padgett \& Notar, 2013; Salmivalli, 2014). Although the actions of "defenders" positively impact bullying, students may end up doing nothing when they witness bullying because they do not know how to intervene (Forsberg, Samuelsson, \& Thornberg, 2014; Hutchinson, 2012). Thus, it is imperative for researchers to investigate how to empower and instruct students to act as "defenders" when they observe bullying.

Although comprehensive, school-wide programs are a standard for practice in bullying interventions (Polanin, Espelage, \& Pigott, 2012; Ttofi, Farrington, Lösel, \& Loeber, 2011), research indicates that these programs are more effective for younger students (Yeager et al., 2015). Additionally, few comprehensive programs include a bystander intervention component (Polanin et al., 2012), and those that do, have been normed on children within the context of the classroom setting (Salmivalli, 2010). Given that high school students do not stay in one classroom, there is a need to "re-think" programs for high school students (Denny et al., 2015). Further, because bystander programs developed for younger students do not yield strong effects for older adolescents, there is a need to "age-up" programs for high school students (Yeager et at., 2015). Additionally, some schools may be unable to adopt comprehensive programs because these types of programs can place a high demand on schools both in terms of time and financial resources (Kiva Antibullying, 2014; Menard \& Grotpeter, 2014). This poses a significant barrier to reducing school bullying and the associated negative consequences of victimization. Thus, brief, stand-alone interventions that target bystander behavior may be well-suited for high schools which may have limited resources.

\section{The STAC Program}

STAC, which stands for "stealing the show," "turning it over," "accompanying others," and "coaching compassion" is a brief, stand-alone bystander program that teaches students to become advocates against bullying by training bystanders to intervene as "defender" (Authors, 2015). The STAC program was adapted from the CARES bystander component of the school-wide, comprehensive program Bully-Proofing (Garrity, Jens, Porter, Sager, \& Short-Camilli, 2004). As part of the Bully-Proofing classroom curriculum, teachers train students to intervene when they observe bullying using CARES strategies which include, "creative problem solving," "adult help," "relate and join," "empathy," and "stand up and speak out" (Garrity et al., 2004, p.117). STAC was developed to shift program coordination and implementation from teachers to school counselors and was designed as a 90-minute training with bi-weekly, 15-minute small group follow-up meetings to place low demands on schools to increase program adoption.

Initial findings with elementary school and middle school students indicate the program is effective in increasing students' knowledge of different types of bullying, knowledge of the STAC strategies, and confidence to intervene in bullying situations (Authors, 2015; Authors, 2016b; Authors, 2016c). Research also indicates that the STAC intervention is effective in reducing bullying perpetration among students who occasionally bully (Authors, 2017a). Although these studies provide support for the STAC intervention, the program was developed for elementary and middle school students. To date, there is no research on the appropriateness of this approach with high school students or how the program may need to be adopted for the high school level.

\section{The Current Study}

Although research examining the STAC intervention demonstrates positive effects at the elementary and middle school level (Authors, 2015; Authors, 2016b; Authors, 2016c; Authors, 2017a), it is not clear that the content of the program, originally designed for younger students, is appropriate for addressing bullying among high school students. Further, to our knowledge, there is no published literature investigating how to modify a bystander bullying intervention to be developmentally appropriate for this age group. Thus, the purpose of this study is to extend the literature by investigating how an existing brief, stand-alone bystander intervention may need to be modified to be appropriate for high school students. Specifically, we were interested in the answering the following research question: "How does the STAC program need to be adapted to be developmentally appropriate for high school students?" To 
This is an author-produced, peer-reviewed version of this article. The final, definitive version of this document can be found online at Journal of Child and Adolescent Counseling, published by Taylor \& Francis. Copyright restrictions may apply .doi: 10.1039/c7ta01026e

achieve this aim, we a) presented the STAC intervention to high school students and b) conducted follow-up focus groups to obtain feedback about the STAC intervention to provide information about how the training may need to be modified for their age group. Because this is a new area of study, and we were interested in descriptions of students' in-depth, inner experience, we used Consensual Qualitative Research (CQR), which is well suited for this type of inquiry (Hill et al., 2005).

\section{Methods}

The research team investigated the in-depth, inner experience of high school students after being trained in the STAC program with the goal of gathering information to modify the program to be developmentally appropriate for this age group. There are several reasons we chose CQR as the methodological approach for our study. First, we selected CQR because it utilizes elements from phenomenology, grounded theory, and comprehensive process (Hill et al., 2005). In particular, $C Q R$ is predominantly constructivist with postmodern influence (Hill et al., 2005), which was a good fit for the project because researchers were interested in the students' perspective of being trained in the STAC program in order to appropriately modify it for high school. Furthermore, CQR's constructivist ontology is consistent with our belief that participants are experts in their experience who can teach us about the complex nature of being trained to intervene when they observe bullying at the high school level. Another reason we selected CQR as our approach is because Hill et al. (2005) recommends that an experienced facilitator should conduct open-ended, semistructured interviews to promote the in-depth exploration of participant's experiences with the phenomenon under investigation, while at the same time, allowing for spontaneous probes that can uncover related experiences and insights adding depth to findings. We developed an open-ended semi-structured interview protocol inquiring into each area of the STAC training encouraging participants to share relevant aspects of their experience with the training. Additionally, the focus group facilitator had experience as a full time school counselor and was also a licensed clinical professional counselor, which allowed her to maintain the integrity of the interview protocol while also facilitating participants' exploration of their experiences with bullying that contributed to our ability to understand how to modify the STAC program to be implemented by high school students. Further, CQR was also a good fit because this approach requires that several team members work together to achieve consensus analyzing complex data (Hill et al., 2005). We had multiple researchers working as a team to analyze data where students described their feelings, opinions, and thoughts about being trained in the STAC program, as well as their experiences with bullying in high school. Achieving agreement by consensus was appealing to the team because it promotes the inclusion of all team members' perspectives about the data.

\section{$\underline{\text { Participants }}$}

The researchers recruited students from a public high school in the Northwestern region of the United States. The high school is in an urban area and includes approximately 1,364 students ( $47 \%$ female, $53 \%$ male), with $71 \%$ of students identifying as White, $16 \%$ Hispanic, 4\% Asian-American, 5\% African-American, and 2\% identify as two or more races. Additionally, $42 \%$ of the students qualify for reduced or free lunch. The school is housed in a district where high school include grades 10 through 12.

The school counselor provided the team with a list of all students registered at the school, including student demographic information (i.e., race, ethnicity, gender, and year in school). Researchers used randomized sampling based on the recommendation of Hill et al. (2005). Researchers used a randomized stratified sampling procedure to select 38 students to participate in the study. Of the 38 students initially selected, $10.5 \%(n=4)$ had withdrawn from the school and $2.6 \%(n=1)$ could not to be reached by the school counselor due to chronic absences. Of the remaining 33 students, we obtained parental consent and subsequent student assent from 27.3\% $(n=9)$. One student was absent from school when researchers conducted the follow-up groups. The final sample $(n=8)$ included five females $(62.5 \%)$ and three males $(37.5 \%)$. Participants ranged in age from $15-17$ years old $(M=16.00$ and $S D=0.76)$, with reported racial backgrounds $87.5 \%$ White and $12.5 \%$ African-American; $37.5 \%(n=3)$ students were $10^{\text {th }}$ graders, $37.5 \%(n=$ $3)$ were $11^{\text {th }}$ graders, and $25 \%(n=2)$ were $12^{\text {th }}$ graders.

\section{$\underline{\text { Researchers }}$}

The research team consisted of three counselor education faculty members, a doctoral counselor education student, and a masters in counseling student. Two faculty members (first and second author) designed the study methodology. Students (third and fourth authors) conducted the STAC program along with an additional six masters in counseling 
This is an author-produced, peer-reviewed version of this article. The final, definitive version of this document can be found online at Journal of Child and Adolescent Counseling, published by Taylor \& Francis. Copyright restrictions may apply .doi: 10.1039/c7ta01026e

students; the doctoral student (third author) facilitated the focus groups and a masters student served as the note-taker. A faculty member (first author) and students (third and fourth authors) analyzed the data and a faculty member (fifth author) served as the external auditor.

Before collecting data, the first, third, and fourth authors discussed their feelings and expectations about bullying in high school and bystander intervention programs including the STAC program. Team members brought different levels of bullying-related clinical and research experience to the discussion. The team members agreed that bullying was a significant problem and agreed to set aside biases and feelings and focus on the data to discover participants' experiences. Further, team members discussed power differentials and how that could influence the data analysis process. The team agreed that each member would share and respond to all domains and core ideas. Additionally, team members decided the doctoral student would lead data analysis meetings to minimize power imbalances and conclusions about the data would be determined based on participant quotations. Further, the team discussed the importance of including an objective external auditor who had no previous involvement with the STAC program to provide a more objective perspective. Our findings must be interpreted within the context of this information.

\section{Procedures}

Student recruitment and implementation of the study procedures occurred during the fall of 2016. All research procedures were approved by the university and school district review boards.

Recruiting Students: The researchers randomly selected students to participate in the study utlizing randomized stratefied sampling procedures. The school counselor met briefly with students selected as a group to discuss the research project and provide an informed consent form to be signed by a parent or guardian and returned to the school counselor. The school counselor followed up with the students who indicated interest and emailed parents with student permission. The school counselor then met with each of the students who had parental consent to explain the research in more detail and obtain student assent. The researchers presented the 90 -minute STAC training to the participants and then conducted two focus groups the following day. The researchers conducted the STAC training in the school's library and the focus groups in an available classroom. The researchers audiorecorded both focus groups for transcription purposes. Each group lasted approximately 45 minutes. The team provided pizza to students at the end of each focus group to incentivize participation.

\section{The STAC Intervention}

The STAC intervention (Authors, 2015) is designed to train students to act as "defenders" on behalf of victims of bullying. The intervention is 90 -minutes and includes didactic training and an experiential role-play component which are used to train the students in the four STAC strategies (for details, see Authors, 2015).

Definitions of Bullying. Trainers present the definition of bullying and the different types of bullying to increase students knowledge and awareness of bulling behavior. Trainers provide the definition of physical, verbal, relationship, and cyberbullying and examples of each type of bullying.

The STAC Strategies. Trainers present each of the four STAC strategies to the students and provide examples of how to use the strategies. The four strategies are:

"Stealing the Show." "Stealing the show" involves using humor to turn students' attention away from the bullying situation. Trainers teach student bystanders to use their sense of humor when they observe bullying to displace the attention away from the target. Trainers provide examples such as students could tell a funny joke, pretend to trip, or act silly.

"Turning it Over." "Turning it over" involves informing an adult about the situation and asking for help. During the training, students identify safe adults at school who can help. Students are taught to always "turn it over" if there is physical bullying taking place or if they are unsure as to how to intervene. 
This is an author-produced, peer-reviewed version of this article. The final, definitive version of this document can be found online at Journal of Child and Adolescent Counseling, published by Taylor \& Francis. Copyright restrictions may apply .doi: 10.1039/c7ta01026e

"Accompanying Others." "Accompanying others" involves the bystander reaching out to the student who was targeted to communicate that what happened is not acceptable, that the student who was targeted is not alone at school, and that the student bystanders cares about them. Trainers teach this to students by providing examples of how they can use this strategy such as approaching a peer after they were targeted and inviting them to go for a walk during recess. This strategy focuses on communicating empathy to the victim.

"Coaching Compassion." "Coaching compassion" involves gently confronting the student who bullies either during or after the bullying incident to communicate that his or her behavior is unacceptable. Additionally, the student bystander encourages the student who bullied to consider what it would feel like to be the target in the situation, thereby fostering empathy toward the target. Bystanders are encouraged to implement "coaching compassion" when they have a relationship with the student who bullied or if the student who bullied is in a younger grade and the bystander believes they will respect them.

STAC Program Activities. Several activities designed to engage students are included in the program. Some activities are used to build report (i.e., matching shapes to locate their assigned table and engaging in ice breakers in which students share something personal). Other activities are designed to engage students in the program (i.e. writing about bullying on posters and using role-plays to act out using the STAC strategies).

Focus Group Interviews. The facilitator utilized an open-ended semi-structured protocol asking participants to reflect on their experience in the STAC training and how the program could be modified to be appropriate for high school students. The facilitator shared that the researchers perceived them as the experts in their experience with bullying in high school and were interested in learning from their experiences to adapt the STAC program for implementation at the high school level. The facilitator encouraged participants to be honest and reminded them they could withdraw at any time without negative consequences.

Researchers developed interview questions corresponding to each area of the STAC training to elicit feedback and explore students' experience with the program. Questions are available by request. The team followed Hill et al.'s (2005) recommendations to develop a detailed semi-structured protocol while also allowing the facilitator to respond spontaneously to participants to help them explore their inner experiences being trained in the program. The facilitator utilized her clinical skills and experience as a high school counselor to encourage deeper discussions among students. Further, she summarized, reflected, and guided dialogue between participants (Hill, 2012). After each focus group, the facilitator and the note-taker recorded their observations, impressions, and biases (Creswell, 2013).

Data Analysis. The first, third, and fourth authors employed CQR methodology (Hill et al., 2005) to analyze the data. The third and fourth authors transcribed the data, and the three team members involved in data analysis read the transcripts for each of the focus groups. Prior to meeting as a team, each member developed initial domains and core ideas individually. Next, the team met three times over a three-week period to arrive at a consensus about domains, core ideas, and frequency categories supported by participant quotations as suggested by Hill et al. (2005). During the first meeting, each researcher shared initial domains followed by each team member commenting, voicing agreement or disagreement. Researchers relied on participants' quotes to resolve disagreements. The third author who led the meetings, wrote down each domain on a note card to provide a visual of the data as recommended by Hill et al. (2005). Researchers discussed emerging core ideas as they talked about each domain and reached consensus on an initial set of domains and core ideas. Researchers repeatedly referred back to the raw data and engaged in crossanalysis to move into a higher level of abstraction (Hill et al., 2005). Further, as suggested by Hill et al. (2005), researchers labeled themes as general (including quotes from all but one participant), typical (more than half of the participants), and variant (including at least two participants). Researchers only included general and typical statements in the core ideas.

Next, the external auditor reviewed the raw data and domains, core ideas, and cross-analysis. The auditor determined the raw data had been appropriately represented in domains and core ideas. She provided the team with written feedback which included "big-picture thinking," offering alternative ways of conceptualizing (Hill et al., 2005, p. 17). The team met with the auditor to further discuss her written comments and referred to the raw data to make decisions regarding how to incorporate her feedback. 
This is an author-produced, peer-reviewed version of this article. The final, definitive version of this document can be found online at Journal of Child and Adolescent Counseling, published by Taylor \& Francis. Copyright restrictions may apply .doi: 10.1039/c7ta01026e

\section{$\underline{\text { Strategies for Trustworthiness }}$}

We utilized multiple strategies to strengthen the trustworthiness of the study based on Hays, Wood, Dahl, and KirkJenkins (2016) recommendations for improving rigor in qualitative studies. First, we engaged in reflexivity to monitor our biases and expectations regarding findings. The researchers recorded memos about their biases and expectations prior to conducting the focus groups. Researchers also discussed their biases and expectations at length throughout the data analysis process. We agreed to keep each other accountable when we perceived biases were potentially interfering with our ability to be objective. All researchers were open and appreciative of feedback and committed to relying on participant quotes to reach consensus. In addition, we engaged in triangulation of the data comparing results between three analysts to cross-analyze the data throughout the data analysis process. Further, we included an external auditor who was not invested in the STAC program in the data analysis process to provide oversight and increase credibility of findings. Finally, we provided a thick description of the research process to provide context for interpretation of findings to increase the trustworthiness of the study.

\section{Results}

The team agreed on six domains with supporting core ideas. Please refer to Table 1 for domains with supporting core ideas and participants' quotes.

\section{Domain 1: Increased Complexity of Bullying}

Participants spoke strongly about the increased complexity of bullying at the high school level. Participants shared that bullying often involves groups of students, in addition to individual students being singled out. For example, a student shared "and it's not like just a single person who is doing it either. It's like groups go after certain groups so I meant its not...like yes there are single people who get bullied but like it's a rare occasion now cuz we're all in groups." Further, participants recognized bullying as a widespread phenomena and spoke about all students being involved in bullying as either a bully or a bystander, for example "everyone's a bystander but also everyone is a bully, like especially with groups. Groups are harder because everyone's a bystander to it but everyone's also doing it at the same time so it's hard to distinguish." Participants also gave examples of bullying or abusive behavior within friendships and romantic relationships adding to the complexity of the phenomena. A participant spoke "I just kept seeing it everywhere. I kept seeing boyfriends telling their girlfriends that they couldn't talk to other boys or 'you can't hang out with your friends anymore, I need to look at your texts'. It can turn into domestic abuse." Additionally, participants often spoke about the covert nature of physical bullying in high school stating that physical bullying occurs frequently through tripping, shoulder checking, or backpack checking among students in the hallways. A students indicated "I tell them to get outta my way. I'll shoulder check people. I'll knock em around with my backpack. I'll tell em to get out of my way because we have 5 minutes to get from this end of the school to the next end of the school."

\section{Domain 2: Cyberbullying and Increased Potential Consequences Related to Social Media}

Participants were clear about the prevalence of cyberbullying among high school students. They stated that high school students spend a great deal of time online and that much of their interactions occurs through social media. For example, a student shared "it [cyberbullying] happens on Twitter and Instagram like a lot." Participants explained that lack of adult supervision online can contribute to the problem, and that cyberbullying often occurs on sites such as Twitter, Instagram, and SnapChat that are less frequented by adults than Facebook. A participant indicated “... [cyberbullying] that's most common in high school. There's a lot of teachers at school so you can't really physically bully people a lot. So they just decide to do it online because things can disappear online." Some participants also expressed concern about the difficulty involved in gathering evidence of cyberbullying because perpetrators can delete their posts, which removes the evidence of the attack. A student spoke "Cyber bullying is probably a lot more common than people see because they could delete the evidence." Further, participants talked about students posting inappropriate pictures and videos of themselves, and discussed the potential severity of exposing illegal activities online, which can result in legal ramifications involving the authorities such as the school resource officers (SROs). For example, a student shared "A lot of that, people over exposing themselves, posting pictures of them drinking and smoking a joint on their SnapChat or on Facebook and then everybody sees that and then you know that's obviously illegal. Obviously. And then the school gets involved and there's not much we can do here besides bring the authorities into it, and that's when the SRO gets involved and it doesn't even necessarily have to be at the school." 
This is an author-produced, peer-reviewed version of this article. The final, definitive version of this document can be found online at Journal of Child and Adolescent Counseling, published by Taylor \& Francis. Copyright restrictions may apply .doi: 10.1039/c7ta01026e

\section{Domain 3: Normalization and Minimization of Bullying}

Most participants talked about teachers and students normalizing bullying in high school. Some participants shared teachers dismiss bullying and that the effects of bullying hurt more than are acknowledged by some teacher and students. One student stated "Mmm, just get like the adults more aware of it cuz I feel like they're like oh you're in high school just brush it off... you're fine. But it really hurts more than that. I guess." Another participant shared "A lot of adults do that [brush off bullying] and it's not like they're mean or anything, they just don't think that's that big of a deal when it's become more of a deal than they think it is." Additionally, some participants discussed how physical bullying can be passed off as normal especially in physical education (PE) class where some level of physical aggression is expected. A student spoke "I mean like you can get really aggressive and just pass it off like 'oh I'm just trying to win.' So, I think that's what happens for the most part in PE. It's just like, you can shove somebody over during like a game of dodgeball and be like 'I didn't see you there.' So it's a lot easier to get away with bullying there [PE]." Participants indicated that often students are not aware of how they are contributing to hurting other students when they minimize or stand by bullying behaviors. Other participants also talked about students unintentionally encouraging bullying by laughing at it. One student shared "Not everyone's gonna take it seriously [bullying behaviors] from how they're raised at home too so that's probably why it still continues. Like not enough people take it [bullying] seriously." Another one indicated "I don't think kids are realizing what they're doing, it's [their behavior] actually encouraging it [bullying] and they're like, I don't think they realize that by encouraging it [bullying], they're allowing other kids to kid hurt. And so it'll just keep happening cuz the bully will think 'oh my friends are laughing, I should go shoulder check this other kid and make them laugh again.' You know like get approval from their friends."

\section{Domain 4: Lack of Support}

Participants' statements strongly reflected high school students feel adults are not doing enough to deal with bullying. Some participants spoke about wishing teachers would be more compassionate toward students and take appropriate action. For example, a participant shared "I just feel like the adults should be more compassionate towards the bullying because I feel like they don't really care.” Almost all participants spoke about feeling like teachers do not care about bullying. For example, one student spoke "Nobody's doing anything about it because it's too hard to prove it and honestly I think the teachers care more about dress code violations than they do about bullying at this point." Participants noted that often teachers seemed preoccupied with their own lives and do not have the time and/or capacity to deal with bullying. A participated said "A lot of the times teachers don't really care. They have a lot going on in their own lives going on. They have their own kids to worry about. They have their own dogs, their own cars, own day, everything else...they don't wanna [intervene]..." Several participants went on to share they feel they must rely on themselves to stop bullying because teachers and peers are not available or willing to help. One student indicated "Yeah a lot of high schoolers do [take care of bullying themselves] cuz they're older and sometimes when you're older you don't always have everyone trying to help you with everything." Another one spoke "Yeah people are just for themselves. They're like I don't want to help you, so like if you're getting bullied no one wants to help you so what do you do I guess."

\section{Domain 5: Appreciation for Strategies to Take Action}

Participants indicated an overall appreciation for all four STAC strategies as potentially useful skills they could use. Participants shared "turning it over" is a necessary strategy that can serve as a last resort for serious situations which needs to remain a part of the intervention. One student stated " "that is the last final option if nothing else works. You go to the authority cuz that's the only thing that's gonna fix." Participants also talked about certain strategies being more appropriate for specific personalities. For example, they commented that "stealing the show" is not well suited for a shy student, but that it would be used by other students. For example, a student said "Yeah, I thought it [stealing the show] was good, I liked the strategies and kind of what they already said but steal the show is a little bit less, not less important, but less used. Just cuz there are a lot of shy people and I don't know very many girls who would do that like she was saying. But some guys would (laughs). I definitely know some guys that would." Participants talked about the importance of using discretion when "accompanying others" because some victims of bullying may not want to talk about the incident. Therefore, participants indicated trainers must emphasize that high school students can use "accompanying others" by spending time with the victim without directly talking about the incident. A student shared "I like it [accompanying others] I don't know. I think supporting others, everyone always needs a friend when they're getting bullied or like in a time of need... I don't know, maybe emphasize that. Be like even if they're not taking it, just always be there for them." Participants spoke about "coaching compassion" as being potentially useful in helping 
This is an author-produced, peer-reviewed version of this article. The final, definitive version of this document can be found online at Journal of Child and Adolescent Counseling, published by Taylor \& Francis. Copyright restrictions may apply .doi: 10.1039/c7ta01026e

a bully realize his or her behavior is inappropriate and unacceptable. For example, a student shared "So you know when you're you have that kind of a steady mindset you can just go like hey that wasn't really nice and I know I have done the same thing but like maybe you should go apologize cuz that was pretty rude and they're probably having a bad day too. So just kinda having that awareness and telling your friends and other people that you see and just not even trying to be rude or condescending about it just telling them like hey, I wouldn't like it I you did that to me and I'm sure you wouldn't like it either."

\section{Domain 6: STAC Training Activities to Help Build Rapport and Increase Awareness}

Participants talked about valuing activities during the STAC training that were designed to build rapport among students. Several participants noted they valued a variety of activities designed to help them get to know one another. For example, a student stated "I liked it [training activity] because it got me more comfortable with my group and felt like I could open up more." Participants also shared that activities helped them become more aware of bullying and what they could do differently to address the problem. For example, a student shared "I agree with both of them [two participants who shared] and you know it [poster activity] was partially an ice breaker which was nice and it was also like something that kind of reminds everyone of things that they've seen in bullying that they've seen and ways they could have dealt with it better if they hadn't dealt with it at all. You know like whether you were the one getting bullied or you were the one seeing someone else you know. I thought that was really neat. I liked that." Participants also indicated engaging in the training activities fosters connections with peers they can carry over to their daily lives in high school so they do not have to feel alone. A student shared "With the snowball activity it would also start a web of like interconnection. So if you have a falling out with friends, you can go back to your interconnections and then you still have friends. So it's not like you're so alone now." Finally, some participants suggested adding a video depicting cyberbullying and in-person bullying to the STAC program to help build awareness and engage students at the high school level. For example, a student said "Videos are always great cuz it's sometimes kids don't always have a very long attention span for talking and so it helps, maybe in the middle of it or something like a video about any of the, anything having to do with this and that might help."

\section{Discussion}

The purpose of this study was to re-think bystander bullying intervention to be developmentally appropriate for high school students. During semi-structured focus groups, high school students reflected on their experiences participating in the STAC intervention and provided feedback regarding how to adapt the program to their age group. Six findings emerged as most salient domains of students experiences.

Our first finding was students spoke about the increased complexity of bullying in high school, identifying it as a group problem impacting different types of relationships including romantic relationships and friendships. As students mature and develop cognitively and socio-emotionally, they may be able to process the more complex dynamics of bullying (Swearer, Martin, Brackett, \& Palacios II, 2016; Yeager et al., 2015) so that they are more aware of bullying extending beyond a single individual being targeted. Additionally, students talked about experiencing bullying as a widespread phenomena involving all students at school. This is consistent with research conducted at the elementary school level where bullying is described as a group phenomenon (Salmivalli, 2010) and all students are involved as either a bully, victim, or bystander (Salmivalli, 2010; Salmivalli 2014).

Our second finding was students spoke about experiencing cyberbullying and increased negative consequences related to social media. According to recent national statistics, students report the highest rates of cyberbullying while in high school (Schneider, O’Donnell, Stueve, \& Coulter, 2012; U.S. Department of Education, 2016). Additionally, studies indicate an association between cyberbullying and negative outcomes for students including increased social anxiety (Juvonen \& Gross, 2008), increased symptoms of depression (Schneider et al., 2012), and suicide attempts (Schneider et al., 2012).

Our third finding was that students believe bullying behaviors are normalized and minimized by peers and teachers. Researchers have found that some students reinforce bullying by providing an audience, laughing, or intentional assisting the perpetrator (Salmivalli, 2014). Additionally, previous studies indicate that teachers perceive bullying as a normal developmental process, where victims are expected to address bullying on their own without adult help (Hektner \& Swenson, 2012; Troop- Gordon \& Ladd, 2015). Researchers have also found a discrepancy between teachers and students' perceptions of frequency of bullying at school, where teachers underestimate the extent to which 
This is an author-produced, peer-reviewed version of this article. The final, definitive version of this document can be found online at Journal of Child and Adolescent Counseling, published by Taylor \& Francis. Copyright restrictions may apply .doi: 10.1039/c7ta01026e

bullying is a problem for students (Bradshaw, Sawyer, \& O’Brennan, 2007). Further, teachers may not perceive indirect forms of bullying (e.g., excluding others and spreading rumors) as seriously as students (Ellis \& Shute, 2007) because these types of bullying can be covert and more difficult for students to prove.

The normalization of bullying by teachers may be related to our next finding that students perceived a lack of support from teachers to address bullying at school. This finding is consistent with previous research suggesting that high school students believe that teachers do not care enough about bullying to take action (Rigby \& Bagshaw, 2003) and that high school student who report bullying to teachers perceive the situation either remains the same or worsens (Fekkes, Pijpers, \& Verloove-Vanhorick, 2005). Further, research indicates teachers may normalize bullying (Hektner \& Swenson, 2012; Troop-Gordon \& Ladd, 2015), and that teacher perceived seriousness of bullying is directly related to the likelihood of intervening (Dedousis-Wallace, Shute, Varlow, Murrihy, \& Kidman, 2014). Additionally, teacher self-efficacy is related to the likelihood of intervening to stop bullying (Dedousis-Wallace et al., 2014) and teachers may not have the necessary knowledge to effectively intervene (Bradshaw et al., 2007). This is particularly important as previous research indicates that when teachers are not effective in stopping bullying, bullying behaviors increase (Veenstra, Lindenberg, Huitsing, Sainio, \& Salmivalli, 2014).

Our next two findings were specific to the STAC the program. Students voiced an appreciation for the STAC program providing strategies they can utilize to take action to stop bullying. Although this is the first time researchers investigated high school students' experience with the STAC program, prior research with middle school-aged boys demonstrates younger students also report positive attitudes towards the STAC program and STAC strategies (Authors, 2017b). In addition, we also found students talked about the importance of training activities designed to build rapport among participants. This is consistent with previous finding that show the importance of developing peer relationships during adolescence (Wang \& Eccles, 2012).

\section{Limitations and Future Research}

Although this study adds to the literature, certain limitation must be noted. The researchers utilized a stratified sampling procedure, however, several students selected were either no longer at the school or did not return signed parental consent. Thus, our sample did not match the school's racial demographics limiting our findings to discovering the experience of White and African-American students. Thus, future studies should use additional methods to increase response rates to achieve a more diverse sample that is representative of the school population. Further, although we followed Hill et al.'s (2005) recommendation to randomly sample a homogeneous group of individuals who have experience with bullying in high school, a purposeful or convenience sample could have resulted in giving voice to a more diverse group of students and increased the number of participants in the study.

Additionally, although the CQR provides a rigorous approach to data analysis (Hill et al., 2005), the researchers utilized focus groups instead of individual interviews. Because this procedure may not yield as rich and in-depth descriptions of inner experiences, conducting one-on-one interviews with participants in future studies may result in richer descriptions of phenomena. Further, although we learned about the students' inner experiences related to participating in the STAC intervention, we chose not investigate students' experiences implementing the STAC strategies in actual bullying situations. This decision was made as the purpose of the current study was to gather information about how the STAC program may need to be modified for this age group prior to implementing the modified program. Future research can then build on this work by implementing the modified STAC program and interviewing high school students about their experiences utilizing the STAC strategies, as well as conducting randomized controlled studies to assess the efficacy of the STAC intervention with this age group.

\section{$\underline{\text { Practical Implications }}$}

Our findings provide important implications for counselors. First, it is important for counselors to understand high school students experience bullying as a complex phenomenon. Because bullying remains prevalent in high school, counselors can screen for exposure to bullying and talk with students about the extent to which they perceive bullying impacts their lives. Another implication is for high school counselors to educate students about cyberbullying and the potential dangers associated with social media. Our findings indicate high school students are interested in intervening on behalf of victims of bullying and are receptive to learning strategies to decrease bullying on campus. Students also shared that they are interested in developing interpersonal relationships that extend beyond their peer group. To 
This is an author-produced, peer-reviewed version of this article. The final, definitive version of this document can be found online at Journal of Child and Adolescent Counseling, published by Taylor \& Francis. Copyright restrictions may apply .doi: 10.1039/c7ta01026e

address these interests, school counselors can incorporate group activities designed to develop meaningful relationships among students from different peer groups to promote expanding students social support networks at school.

Results of this study also suggest that high school students believe that teachers normalize and minimize bullying behavior. Counselors are well positioned to raise teachers' awareness of bullying, including prevalence and negative associated outcomes for students. Research supports the effectiveness of professional development presentations on bullying for teachers, particularly when information focuses on feelings to foster empathy rather than on facts about bullying (Dedousis-Wallace et al., 2014). School counselors can help teachers reflect on their own experiences with bullying to help teachers recognize their attitudes and beliefs that may prevent them from taking action (Authors, 2016a). This could be accomplished through informal counselor-led discussions or through formal professional development presentations at staff meetings. Engaging the principal as an ally in emphasizing the importance of not minimizing bullying behavior may also be important to impact the culture of the school.

Findings from this study also provide important information for modification of the STAC intervention program to be appropriate for high school students. First, the program developers need to include more examples of bullying that are age-appropriate to reflect both the more complex dynamics of bullying, as well as different types of bullying experienced by high school students. Examples of bullying can be modified to include bullying within group settings, friendships and romantic relationships, and covert examples of physical bullying. Developers can also modify roleplays to include these types of bullying when training the use of the STAC strategies. Cyberbullying should also be emphasized due to its prevalence at the high school level. For example, trainers can teach students to document evidence of cyberbullying and "turn it over" to appropriate authorities, including teachers and SROs. Trainers can also talk about the importance of taking screen shots or photos of humiliating or inappropriate social media posts immediately.

Findings also suggest that program developers could create a video presentation to help engage students and increase awareness of different types of bullying behavior. A video could be created using student actors demonstrating both in-person and cyberbullying behavior, as well as ways to respond to different types of bullying using STAC strategies. Alternatively, developers could use already produced videos that can be easily accessed on YouTube. For example, Cyber Bullying Virus (https://www.youtube.com/watch?v=vmQ8nM7b6XQ) depicts cyberbullying as a virus and provides examples of bullying on Facebook. This video gives examples of ways to stand up to cyberbullying including giving courage, compassion, and bravery, which could be integrated into the training of the STAC strategy "accompanying others" and "coaching compassion."

A final implication for modification of the STAC program is related to the feedback that school personnel minimizes and normalizes bullying. As discussed above, counselors can informally or formally educate teachers and other staff on the prevalence and impact of bullying, and what school personnel can do to reduce bullying on campus. Alternatively, a teacher module could be built into the STAC program for high school students. In this module, counselors could educate teachers about bullying and about the STAC strategies. The training would emphasize the strategy "turning it over," explaining to the teacher his or her role in helping student bystanders intervene when they observe bullying. Further, as part of the program, trainers could teach teachers to use other STAC strategies to address school bullying when students have "turned it over" to them. For example, teachers could utilize "accompanying others" by listening and speaking to students when they report bullying. Teachers can also be trained to communicate to students that bullying is not acceptable, and that they will take the time to support students in addressing bullyingrelated concerns. Additionally, teachers can use "turning it over" to inform the SRO, principal, or bullying specialist about the bullying incident. Although adding a teacher module to the STAC intervention will increase the time and resources needed to administer the program, it may be an important addition for the high school level.

Finally, our findings also have implications for counselor educators. First, it is important to raise the awareness of counselors-in-training regarding bullying as a prevalent problem for students in high school. Additionally, similar to implications for counselors working with school teachers, counselor education faculty can help counselors-in-training reflect on their own experiences with bullying to help them recognize their attitudes and beliefs that may prevent them from taking action (Authors, 2016a). Faculty can also train counselors-in-training to assess high school students' involvement with bullying as either a bystander, victim and/or perpetrator. For example, counselors-in-training can learn about the characteristics and types of bullying students talk about as prevalent in high school such as (a) the complexity of bullying and its pervasiveness among peer groups and romantic relationships and friendship, (b) the 
This is an author-produced, peer-reviewed version of this article. The final, definitive version of this document can be found online at Journal of Child and Adolescent Counseling, published by Taylor \& Francis. Copyright restrictions may apply .doi: 10.1039/c7ta01026e

increased prevalence of cyberbullying, and (c) the covert nature of physical bullying. Furthermore, it is important for counselors-in-training to learn to empower high school students to reduce bullying because students spoke about their desire to make a difference. Specifically, counselors-in-training can learn the STAC strategies as an approach to equipping high school students to intervene when they witness bullying at school.

\section{Conclusion}

This study investigated in-depth, inner experiences of high school students trained in the STAC program with the goal of gathering feedback to inform program modifications for this age group. Overall, findings provide information about high school students' perceptions of bullying including the complex nature of bullying in high school, prevalence of cyberbullying and potential negative consequences associated with social media, normalization and minimization of bullying by teachers and peers, and lack of teacher support to address the problem of bullying. Further, findings provide information for modifying the STAC program to be appropriate for high school students by including examples of bullying focusing on group dynamics and peer relationships, cyberbullying, and including videos as part of the training. This study serves as a first step in the development of a brief, counselor-led bystander intervention for high school students.

\section{References}

Authors. (2015). A bystander bullying psychoeducation program with middle school students: A preliminary report. The Professional Counselor, 5, 486-500. doi:10.15241/am.5.4.486

Authors. (2016a). Bullying: How counselors can intervene. Counseling Today, 58, 39-43.

Authors. (2016b). Training elementary school students to intervene as peer-advocates to stop bullying at school: A pilot study. Journal of Creativity in Mental Health, 11, 353-365.

Authors. (2016c). A randomized control study of a bystander bullying intervention program. Manuscript submitted for publication.

Authors. (2017a). Training students who occasionally bully to be peer advocates: Is a bystander intervention effective in reducing bullying behavior? Journal of Child and Adolescent Counseling, 1-13. doi:http://dx.doi.org/10.1080/23727810.2016.1277116

Authors. (2017b). The phenomenological lived experience of student-advocates acting as "defenders" to stop bullying. Journal of Humanistic Counseling, 56, 53-71. doi: 10.1002/johc.12044

Bradshaw, C. P., Sawyer, A. L., \& O’Brennan, L. M. (2007). Bullying and peer victimization at school: Perceptual differences between students and school staff. School Psychology Review, 36, 361-382.

Center for Disease Control and Prevention, Division of Adolescent and School Health. (2016a). Trends in the prevalence of behaviors that contribute to violence National YRBS: 1991-2015. Retrieved from https://www.cdc.gov/healthyyouth/data/yrbs/pdf/trends/2015_us_violence_trend_yrbs.pdf

Center for Disease Control and Prevention, National Center for Injury Prevention and Control. (2016b). Understanding bullying: Fact sheet 2016. Retrieved from https://www.cdc.gov /violenceprevention/youthviolence/bullyingresearch/

Creswell, J. W. (2013). Qualitative inquiry and research design choosing among five approaches (3rd ed.). Los Angeles, CA: SAGE Publications.

Datta, P., Cornell, D., \& Huang, F. (2016). Aggressive attitudes and prevalence of bullying bystander behavior in middle school. Psychology in the Schools, 53, 804-516. doi:10.1002/pits.21944

Dedousis-Wallace, A., Shute, R., Varlow, M., Murrihy, R., \& Kidman, T. (2014). Predictors of teacher intervention in indirect bullying at school and outcome of a professional development presentation for teachers. Educational Psychology, 34, 862-875. doi:10.1080/01443410.2013.785385

Denny, S., Peterson, E. R., Stuart, J., Utter, J., Bullen, P., Fleming, T., . . Milfont, T. (2015). Bystander intervention, bullying, and victimization: A multilevel analysis of New Zealand high schools. Journal of School Violence, 14, 245-272. doi:10.1080/15388220.2014.910470

Dukes, R. L., Stein, J. A., \& Zane, J. I. (2010). Gender differences in the relative impact of physical and relational bullying on adolescent injury and weapon carrying. Journal of School Psychology, 48, 511-532.

Ellis, A., \& Shute, R. (2007). Teacher responses to bullying in relation to moral orientation and seriousness of bullying. British Journal of Educational Psychology, 77, 649-663.

Evans, C. B. R., Fraser, M. W., \& Cotter, K. L. (2014). The effectiveness of school-based bullying prevention programs: A systematic review. Aggression and Violent Behavior, 19, 532-544. 
This is an author-produced, peer-reviewed version of this article. The final, definitive version of this document can be found online at Journal of Child and Adolescent Counseling, published by Taylor \& Francis. Copyright restrictions may apply .doi: 10.1039/c7ta01026e

Forsberg, C., Samuelsson, M., \& Thornberg, R. (2014). Bystanders to bullying: Fourth- to seventh-grade students' perspectives on their reactions. Research Papers in Education, 29, 557-576. doi:10.1080/02671522.2013.878375

Fekkes, M., Pijpers, F. I., \& Verloove-Vanhorick, S. P. (2005). Bullying: who does what, when and where? Involvement of children, teachers and parents in bullying behavior. Health Education Research, 20, 81-91.

Garrity, C., Jens, K., Porter, W., Sager, N., \& Short-Camilli, C. (2004). Bully-proofing your school: Working with victims and bullies in elementary schools (3rd ed.). Longmont, CO: Sopris West.

Hays, D., Wood, C., Dahl, H., \& Kirk-Jenkins, A. (2016). Methodological rigor in Journal of Counseling \& Development qualitative research articles: A 15-year review. Journal of Counseling \& Development, 94, 172-183.

Hektner J. M., \& Swenson C. A. (2012). Links from teacher beliefs to peer victimization and bystander intervention: Tests of mediating processes. The Journal of Early Adolescence, 4, 516-536. doi:10.1177/0272431611402502

Hertz, M. F., Donato, I., \& Wright, J. (2013). Bullying and suicide: A public health approach. Journal of Adolescent Health, 53, S1-S3. doi:10.1016/jadohealth.2013.05.002

Hill, C. E., Knox, S., Thompson, B. J., Williams, E. N., Hess, S. A., \& Ladany, N. (2005). Consensual qualitative research: An update. Journal of Counseling Psychology, 52, 196-205. doi:10.1037/0022-0167.52.2.196

Hutchinson, M. (2012). Exploring the impact of bullying on young bystanders. Educational Psychology in Practice, 28, 425-442. doi:10.1080/02667363.2012.727785

Juvonen, J. \& Gross, E. F. (2008). Extending the school grounds? Bullying experiences in cyberspace. Journal of School Health, 78, 496-505. doi:10.2105/AJPH.2011.300308

KiVa Antibullying (2014). Frequently asked questions. Retrieved from http://www.kivaprogram.net/faq

Lomek, A. B., Kleinman, M., Attschuler, E., Morrocco, F., Amakawa, L., \& Gould, M. S. (2011). High school bullying as a risk for later depression and suicidality. Suicide Life Threat Behavior, 41, 501-516.

Menard, S., \& Grotpeter, J. K. (2014). Evaluation of bully-proofing your school as an elementary school antibullying intervention. Journal of School Violence, 13, 188-209. doi:10.1080/15388220.2013.840641

Padgett, S., \& Notar, C. E. (2013). Bystanders are the key to stopping bullying. Universal Journal of Educational Research, 1, 33-41. doi:10.13189/ujer.2013.010201

Petrosino, A., Guckenburg, S., DeVoe, J., and Hanson, T. (2010). What characteristics of bullying, bullying victims, and schools are associated with increased reporting of bullying to school officials? (Issues \& Answers Report, REL 2010-No. 092). Retrieved from Institute of Education Sciences, Regional Educational Laboratory website: http://ies.ed.gov/ncee/edlabs/regions/northeast/pdf/rel_2010092.pdf

Polanin, J. R., Espelage, D. L., \& Pigott, T. D. (2012). A meta-analysis of school-based bullying prevention programs' effects on bystander intervention behavior. School Psychology Review, 41, 47-65.

Polanin, M., \& Vera, E. (2013). Bullying prevention and social justice. Theory Into Practice, 52, 303-310. doi: $10.1080 / 00405841.2013 .829736$

Rigby, K. \& Bagshaw, D. (2003) Prospects of adolescent students collaborating with teachers in addressing issues of bullying and conflict in schools. Educational Psychology, 32, 535-546.

Rigby, K. (2007). Children and bullying: How parents and educators can reduce bullying at school. Oxford: WileyBlackwell.

Rivers, I., Poteat, V. P., Noret, N., \& Ashurst, N. (2009). Observing bullying at school: The mental health implications of witness status. School Psychology Quarterly, 24, 211-223. doi:10.1037/a0018164

Salmivalli, C. (2010). Bullying and the peer group: A review. Aggression and Violent Behavior, 15, 112-120. doi:10.1016/j.avb.2009.08.007

Salmivalli, C. (2014). Participant roles in bullying: How can peer bystanders be utilized in interventions? Theory Into Practice, 53, 286-292. doi:10.1080/00405841.2014.947222

Salmivalli, C., Lagerspet, K., Björkqvist, K., Österman, K., \& Kaukiainen, A. (1996). Bullying as a group process: Participant roles and their relations to social status within the group. Aggressive Behavior, 22, 1-15. doi:10.1002/(SICI)1098-2337(1996)22:13.0.CO;2-T

Salmivalli, C., Voeten, M., \& Poskiparta, E. (2011). Bystanders matter: Associations between reinforcing, defending, and the frequency of bullying behavior in classrooms. Journal of Clinical Child \& Adolescent Psychology, 40, 668-676. doi:10.1080/15374416.2011.597090

Schneider, S. K., O’Donnell, L., Stueve, A., \& Coulter, R. W. S. (2012). Cyberbullying, school bullying, and psychological distress: A regional census of high school students. American Journal of Public Health, 102, 171-177. 
This is an author-produced, peer-reviewed version of this article. The final, definitive version of this document can be found online at Journal

of Child and Adolescent Counseling, published by Taylor \& Francis. Copyright restrictions may apply .doi: 10.1039/c7ta01026e

Swearer, S. M., Martin, M., Brackett, M., \& Palacios II, R. A. (2016). Bullying intervention in adolescence: The intersection of legislation, policies, and behavioral change. Adolescent Research Review, 1-13. doi:10.1007/s40894-016-0037-9

Troop-Gordon, W., \& Ladd, G. W. (2015). Teachers' victimization-related beliefs and strategies: Associations with students' aggressive behavior and peer victimization. Journal of Abnormal Child Psychology, 43, 45-60. doi:10.1007/s10802-013-9840-y

Ttofi, M. M., Farrington, D. P., Lösel, F., \& Loeber, R. (2011). Do the victims of school bullies tend to become depressed later in life? A systematic review and meta-analysis of longitudinal studies. Journal of Aggression, Conflict and Peace Research, 3, 63-73. doi:10.1108/17596591111132873

U.S. Department of Education: National Center for Educational Statistics. (2015). Student reports of bullying and cyber-bullying: Results from the 2013 school crime supplement to the national crime victimization survey (NCES 2015-056). Retrieved from https://nces.ed.gov/pubs2015/2015056.pdf

U.S. Department of Education, National Center for Education Statistics. (2016). Indicators of School Crime and Safety: 2015 (NCES 2016-079). Retrieved from https://nces.ed.gov /programs/digest/d15/tables/dt15_230.40.asp

Veenstra, R., Lindenberg, S., Huitsing, G., Sainio, M., \& Salmivalli, C. (2014). The role of teachers in bullying: The relation between antibullying attitudes, efficacy, and efforts to reduce bullying. Journal of Educational Psychology, 106, 1135-1143.

Wang, M. T., \& Eccles, J. S. (2012). Social support matters: Longitudinal effects of social support on three dimensions of school engagement from middle to high school. Child Development, 83, 877-895. doi:10.1111/j.1467-8624.2012.01745.x

Yeager, D. S., Fong, C. J., Lee, H. Y., \& Espelage, D. L. (2015). Declines in efficacy of anti-bullying programs among older adolescents: Theory and a three-level meta-analysis. Journal of Applied Developmental Psychology, 37, 36-51. doi:10.1016/j.appdev.2014.11.005 